\title{
PERCEPÇÃO DE ADOLESCENTES INFRATORAS SUBMETIDAS À AÇÃO SOCIOEDUCATIVA SOBRE ASSISTÊNCIA À SAÚDEA
}

\author{
Perception of j uvenile delinquents submitted to socio-educational action on health care \\ Percepción de adolescentes infractoras sometidas a la acción socio-educativa sobre \\ asistencia a la salud
}

Estela Maria Leite Meirelles Monteiro ${ }^{1}$

Ana Karina de Andrade Araújo ${ }^{4}$

\author{
Carlos Alber to Domingues do Nascimento ${ }^{2}$ \\ Dannilo Rafael Bezerra do Carmo ${ }^{5}$
}

Antonio José de Almeida Filho ${ }^{3}$

Islan Moisalye Barbosa Gomes ${ }^{6}$

\section{RESUMO}

0 estudo tem como objetivos conhecer a percepção de adolescentes infratoras submetidas à ação socioeducativa sobre assistência à saúde prestada; identificar a percepção das adolescentes quanto aos fatores que contribuíram para o seu processo de institucionalização; levantar a percepção delas sobre sua saúde física e emocional e conhecer as expectativas dessas adolescentes em relação ao seu futuro. Pesquisa qualitativa de caráter descritivo, que utilizou a técnica do Discurso do Sujeito Coletivo (DSC) para apresentação dos resultados. As adolescentes institucionalizadas são capazes de relatar os cuidados de saúde disponibilizados, ao mesmo tempo que denunciam a necessidade de continuidade desses cuidados, com ênfase nas ações de educação em saúde. A importância da inserção do enfermeiro é evidenciada pelo planejamento de ações em saúde que atendam às reais necessidades desse grupo etário, atuando na promoção da saúde e propiciando ações de empoderamento no exercício de uma cidadania solidária.

Palavras-chave: Adolescente Institucionalizado. Promoção da Saúde. Assistência à Saúde. Comunidades Vulneráveis. Enfermagem.

\begin{abstract}
The study aims at assessing the perception of adolescent offenders subjected to socio-educational action on health care provided, identify the perception of adolescents regarding factors that contributed to its institutionalization process; raise awareness of them on their physical and emotional, and meet the expectations of these teenagers in relation to their future. It's a qualitative research with a descriptive nature, using the technique of the Collective Subject Discourse (CSD) for presentation of results. The institutionalized adolescents are able to report health care available, while denouncing the need for the continuity of care, with emphasis on the actions of health education. The importance of the inclusion of nurses is evidenced by the planning of public health that meets real needs of this age group, working in health promotion and providing actions to empower the enjoyment of solidarity.
\end{abstract}

Keywords: Adolescent, Institutionalized. Health Promotion. Delivery of Health Care. Vulnerable Groups. Nursing.

\section{Resumen}

El estudio tiene como objetivos conocer la percepción de adolescentes infractoras sometidas a la acción socio-educativa sobre asistencia a la salud prestada; identificar la percepción de estas sobre los factores que contribuyeron para su proceso de institucionalización; levantar la percepción de las mismas sobre su salud física y emocional; y conocer sus expectativas de futuro. Investigación cualitativa de carácter descriptivo, que utilizó la técnica del Discurso del Sujeto Colectivo (DSC) para presentar los resultados. Las adolescentes institucionalizadas son capaces de relatar los cuidados de salud disponibles y al mismo tiempo denunciar la necesidad de continuidad de estos cuidados, con énfasis en las acciones de educación en salud. La importancia de la inserción del enfermero es evidenciada por la planificación de acciones en salud que atiendan las necesidades reales de este grupo, actuando en la promoción de la salud y propiciando acciones de habilitación en el ejercicio de una ciudadanía solidaria.

Palabras clave: Adolescente Institucionalizado. Promoción de la Salud. Prestación de Atención de Salud. Comunidades Vulnerables. Enfermería.

\footnotetext{
${ }^{1}$ Enfermeira. Doutora em Enfermagem pela UFC. Docente do Programa Associado de Pós-Graduação em Enfermagem UPE/UEPB, nível Mestrado, e da Faculdade de Enfermagem Nossa Senhora das Graças - FENSG/UPE. Líder do Grupo de Estudos e Pesquisas Enfermagem na Promoção a Saúde de populações vulneráveis (GEPEV-CNPq). Recife-PE. Brasil. E-mail: estelapf2003@yahoo.com.br,2Psicólogo. Doutor em Letras pela Universidade Federal de Pernambuco. Professor Adjunto da Faculdade de Enfermagem Nossa Senhora das Graças da Universidade de Pernambuco (FENSG-UPE). Membro do GEPEV-CNPq. Recife-PE. Brasil. E-mail: minguesnascimento@hotmail.com, ${ }^{3}$ Enfermeiro. Doutor em Enfermagem pela EEAN/UFRJ. Professor Adjunto da Escola de Enfermagem Anna Nery da Universidade Federal do Rio de Janeiro. Líder do Grupo de Estudos e Pesquisa Trajetória do Cuidado de Enfermagem em Espaços Especializados - CNPq. Rio de Janeiro-RJ. Brasil. E-mail: ajafilhos@gmail.com, ${ }^{4}$ Enfermeira. Egressa da Faculdade de Enfermagem Nossa Senhora das Graças da Universidade de Pernambuco (FENSG-UPE). Recife - PE. Brasil. E-mail: anakarina_araujo@hotmail.com5Enfermeiro. Egresso da Faculdade de Enfermagem Nossa Senhora das Graças da Universidade de Pernambuco (FENSG-UPE). Recife-PE. Brasil. E-mail: dannilo_rafael@hotmail.com6 Enfermeiro. Egresso da Faculdade de Enfermagem Nossa Senhora das Graças da Universidade de Pernambuco (FENSG-UPE). Recife-PE. Brasil. E-mail: islangomes@hotmail.com
} 


\section{INTRODUÇÃO}

A adolescência caracteriza-se por um momento de vivências associadas a profundas transformações físicas e psíquicas. Trata-se de uma etapa de transição entre a vida infantil e a vida adulta, na qual a maior ou menor elaboração dos conflitos subjacentes a estas vivências pode acarretar uma condição de risco.

Ao se falar sobre adolescência e juventude, as representações que imediatamente emergem são aquelas vinculadas à noção de crise, como um problema social a ser resolvido, que merece atenção pública, especialmente em relação à promoção, prevenção e recuperação da saúde. Situações como gravidez precoce, contaminação pelo Vírus da Imunodeficiência Humana (HIV) ou outras Doenças Sexualmente Transmissíveis (DSTs), uso de drogas ilícitas e risco de morte diante da violência são elementos fortemente presentes no discurso da sociedade sobre 0 adolescente. ${ }^{1}$

A situação de vulnerabilidade parece, assim, definir e circunscrever negativamente esse período da vida, gerando ações e comportamentos preconceituosos em relação aos adolescentes. Mas também há uma realidade efetiva e concreta: trata-se de um período no qual, sem dúvida, se observa um alto risco de adoecimento físico e psíquico. Risco que, considerando as experiências singulares dos adolescentes, exige perspectivas de abordagens específicas. ${ }^{2}$ Desta forma, exige-se dos profissionais que the prestam assistência 0 conhecimento das peculiaridades inerentes ao seu momento vital.

A origem da delinquência está vinculada a fatores de risco oriundos de condições econômicas, de ausência de políticas públicas, das drogas, e mesmo de aspectos sociopsicologicos. ${ }^{3}$ 0 termo delinquência juvenil é a expressão internacionalmente utilizada para referir os delitos cometidos por adolescentes. No Brasil, após a promulgação do Estatuto da Criança e do Adolescente (ECA), ${ }^{4}$ emprega-se o termo infração. 0 adolescente infrator é responsabilizado pelos seus atos através das medidas socioeducativas, dentre as quais temos a semiliberdade. $^{5}$

Diante dessas circunstâncias, o adolescente necessita reconhecer-se como um ser social e, portanto, possuidor de direitos e deveres, indo além das medidas socioeducativas, necessitando de uma assistência à saúde especializada. No entanto, com o intuito de prestar uma assistência universal, acessível e de qualidade, baseada na promoção da saúde, prevenção de doenças e recuperação dos indivíduos, o Sistema Único de Saúde (SUS) visualiza o usuário de forma integral, atendendo desta forma a real necessidade da população nas questões de saúde enquanto direito de cidadania. ${ }^{6}$

De tal forma, o SUS visa romper com o modelo biomédico e assumir o biopsicossocial, no qual não vê meramente a saúde do indivíduo como ausência de doença ou incapacidade. Propõe uma nova compreensão do ser humano, na qual a saúde passa a ser o estado de equilibrio e o bem-estar físico, mental, social, espiritual e intelectual, além da percepção individual e sua participação na coletividade. ${ }^{?}$

Nesse contexto, o enfermeiro na sua formação profissional deve desenvolver habilidades que o faça capaz de atender as especificidades do ser adolescente do gênero feminino, permitindo a atuação do profissional muito além da prevenção de doenças ao garantir sua atuação na promoção à saúde.

0 tema em estudo é de grande relevância já que seus resultados contribuirão para promover medidas de assistência à saúde que proporcionem o entendimento da situação de vulnerabilidade que envolve o ser adolescente feminino, possibilitando uma assistência integral e humanizada a esse grupo etário com ênfase na promoção à saúde.

Diante do exposto, o estudo tem como objetivos: compreender as percepções das adolescentes infratoras submetidas à ação socioeducativa de semiliberdade, sobre o cuidado a sua saúde física e mental; e apreender as expectativas dessas adolescentes em relação ao seu futuro.

\section{PROCEDIMENTOS METODOLÓGICOS}

0 presente estudo fundamentou-se em uma abordagem qualitativa de natureza descritiva e exploratória. Neste tipo de estudo, prioriza-se o levantamento de informações que permitam apreender o universo de significados - motivos, crenças, valores e atitudes - relacionados ao fenômeno

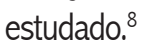

0 estudo teve como cenário a Fundação de Atendimento Socioeducativo (FUNASE), instituída pela Lei № .132 de 11/ 12/2008, vinculada à Secretaria de Desenvolvimento Social e Direitos Humanos, com natureza de fundação, patrimônio próprio e autonomia administrativa e financeira, com sede e foro no Município e Comarca do Recife, capital do Estado de Pernambuco. ${ }^{9}$

Este estudo foi desenvolvido com 14 adolescentes cadastradas e atendidas na Casa de Semiliberdade feminina da cidade do Recife - PE, que praticaram algum ato infracional, sendo submetidas a medidas socioeducativas. Nessa instituição, havia uma população total de 17, entretanto, a amostra foi definida considerando-se os seguintes critérios de inclusão: (a) idade compreendida entre 12 e 18 anos; (b) sexo feminino; (c) sob medidas socioeducativas (semiliberdade); (d) interesse em participar do estudo, com anuência formal e mediante a assinatura do Termo de Consentimento Livre Esclarecido (TCLE) em consonância com a resolução 196/96 ${ }^{10}$; (e) não evadir-se da instituição durante o desenvolvimento da pesquisa.

Os dados foram coletados através do agendamento com a assistente social da instituição, conforme os horários disponíveis das adolescentes. Dessa forma, a etapa de coleta de dados ocorreu nos meses de abril a maio de 2010, havendo uma articulação na utilização da técnica de entrevista, com o 
uso da gravação e a observação assistemática, com registro em diário de campo, de modo a contribuir com a fidedignidade dos dados apreendidos.

A entrevista foi desenvolvida com aplicação de um formulário semiestruturado com os seguintes tópicos: a) o relacionamento sociofamiliar; b) o convívio no ambiente institucional; c) medidas de assistência à saúde; d) percepções sobre o comportamento sexual; e) percepções sobre o uso de drogas; ef) expectativas das adolescentes quanto ao futuro.

Os dados coletados foram organizados e analisados segundo o método do Discurso do Sujeito Coletivo (DSC). A proposta compreende a utilização de figuras metodológicas que resgatam e organizam as significações do discurso coletivo a partir do discurso individual. Para tanto, tem-se as seguintes etapas: a) Identificação de Expressões-Chave (E-Ch) - trechos que melhor identificam e descrevem o conteúdo significativo e comum aos diversos indivíduos; b) Síntese das Ideias (entrais (ICS) - fórmulas sintéticas que descrevem o significado (comum, complementar ou oposto) presente nos discursos; c) Estabelecimento das Ancoragens (ACS) - formulações sintéticas decorrentes das marcas discursivas que permitem identificar e articular o contexto ideológico subjacente ao discurso formulado; e d) Edição dos Discursos do Sujeito Coletivo (DSCs) - articulação das E-Ch e suas respectivas ICs. ${ }^{11}$

Em uma primeira etapa, cada pesquisador realizou, individualmente, a identificação preliminar das E-Ch e das ICs, as quais, uma vez comparadas, acarretaram o estabelecimento daquelas definitivas. Em função destas, realizou-se a segunda etapa, a qual compreendeu, inicialmente, uma edição prévia dos DSCs por cada pesquisador para, em seguida, comparandoas, realizar a edição final dos DSCs. ${ }^{12}$

A pesquisa foi avaliada pelo Comitê de Ética em Pesquisa da Universidade de Pernambuco que emitiu parecer favorável CAAE: 0003.0.097.000-10.

\section{ANÁLISE E DISCUSSÕES DOS DADOS}

\section{Caracterização dos sujeitos do estudo}

A faixa etária das adolescentes, sob medidas socioeducativas em regime de semiliberdade, variou de 14 a 18 anos. A renda familiar predominante era de um salário mínimo a dois salários e meio. A maioria das adolescentes possui uma constelação familiar referencialmente matriarcal, na qual a figura materna, muitas vezes, é citada como a única representante do núcleo familiar. Todas as participantes do estudo estão cursando o ensino fundamental, e algumas também estão participando de cursos profissionalizantes ofertados pelo estado.

A pena a qual estão submetidas está diretamente relacionada ao comportamento, sendo fornecido um relatório pela instituição que as acompanham a cada três meses, sendo este encaminhado ao Juiz da Vara da Infância e Juventude. Os relatórios subsidiam a avaliação periódica quanto ao tempo da medida, não podendo ultrapassar três anos, salvo em casos

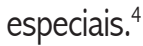

A partir da apreensão dos dados, emergiram seis categorias: o relacionamento sociofamiliar; vivência no mundo das drogas; o processo de institucionalização; percepção sobre o comportamento sexual; medidas de assistência a saúde; expectativas das adolescentes quanto ao futuro.

\section{IC I - 0 relacionamento sociofamiliar}

Compreendendo todas as transformações existentes na adolescência, fica claro que esta etapa do ciclo evolutivo caracteriza-se pela formação da identidade, sendo permeada por mudanças, reformulações subjetivas e ressignificações de diversas ordens, ou seja, o adolescente necessita reescrever seus sentimentos, bem como seus vínculos primários em relação às figuras familiares, revisando assim suas experiências de vida e firmando sua identidade. ${ }^{13}$

Os laços familiares para as adolescentes são estruturantes, pois é com as figuras paternas e maternas que vivenciam muitos de seus conflitos. Um dos aspectos mais significativos destes é o luto pelos pais, momento em que as adolescentes se põem na posição ambígua de lidar com uma representação dos pais, que agora se põem como aqueles da infância, que lhes prestavam cuidado; em outro aspecto, querem ser independentes para ter sua autonomia. A assunção da vida adulta pressupõe a perda dos pais da infância.

No caso das adolescentes infratoras, observa-se uma situação de risco que já se efetivou, seja por questões de ordem individual, familiar, social ou cultural. As medidas socioeducativas, como se deduz da própria denominação dada, visam, mais do que punir, desenvolver ações que assegurem ao adolescente restituir seu desenvolvimento segundo condições que lhe permitam a integração no contexto social e familiar.

Em seus depoimentos, as adolescentes demonstram a importância de seus familiares ao rememorarem seus vínculos e experiências familiares, como nos gestos com as mãos, expressões faciais, risos incontroláveis, olhos lacrimejando e falas interrompidas, principalmente em sua condição atual de infratora, de modo que, em alguns discursos, foi apresentada certa "neutralidade familiar" e até evidenciada uma fuga da realidade, diante da recusa inconsciente dos conflitos intrafamiliar.

DSC: 0 ambiente familiar não desvelado, no discurso das adolescentes:

Éótimo. Eu gosto de ir para casa. Minha família me dá apoio, me ajuda muito e me dá muito conselho. 0 povo lá de casa me aceita como eu sou. Eu tenho minha liberdade. 0 pessoal gosta de me receber, não tem discussão e nem intriga com ninguém, todos 
são unidos. Lá é bom, toda a minha família quer que eu volte para casa.

É importante observar que a fragilidade dos vínculos afetivos com a família faz o adolescente ter uma maior probabilidade de se envolver em infrações, ou, no caso das participantes, reincidir em sua ocorrência. ${ }^{14}$ Alguns depoimentos registram a ausência desses laços estruturantes, parecendo desencadear-se uma vivência de exclusão afetiva e, ao mesmo tempo, um autoconceito negativo, condições propícias para a reincidência:

DSC: A rejeição sociofamiliar à adolescente infratora:

Quando volto para casa, a relação com minha familia não é muito boa. Sou discriminada por alguns deles. A partir do momento que a gente entra nesse mundo, nessa vida, ninguém mais acredita em você, todos ficam pensando que a pessoa vai ser a mesma que era antes, do mesmo jeito, que nunca muda. Às vezes, eles vêm me xingando e eu não gosto(...) Os amigos que eu tinha antes de vir para casa fugiram todos. Eu não tenho amigo... assim, os que se diziam amigos da pessoa, mas não eram, queriam ver sóo mal. Quando a pessoa tá num lugar assim, ninguém quer saber não, meu amigo! E quando eu volto para casa e vou visitá-los, suas mães mandam se afastar de mim (...) aí eu abandonei todos. A única pessoa que é por mim é minha mãe, minha amiga, a única que, quando preciso, posso contar. Algumas pessoas da minha família viraram as costas para mim, mas os que me apoiam representam tudo, são a minha vida!

Além do ambiente familiar, a inserção grupal, ou seja, o convívio com os quais partilham dos mesmos interesses, também é de extrema relevância. Muitos adolescentes, pela própria fase na qual está experienciando, desejam a liberdade e autonomia dos pais, muitas vezes opondo-se as regras sociais. Os amigos compõem um grupo fundamental para os adolescentes, no qual buscam uma independência e uma libertação dos pais. Os amigos, portanto, são uma fonte de busca de referência que, positiva ou negativamente, influenciam diretamente no desenvolvimento de suas atitudes e comportamentos.

Vale destacar um estudo que evidenciou a falta de abertura para o diálogo que os adolescentes têm com os familiares, o que, muitas vezes, concorre para que eles recorram aos amigos, situação que pode desencadear atitudes de vulnerabilidade pelo aconselhamento inadequado. ${ }^{15}$

Compreendendo as adolescentes infratoras como um grupo vulnerável, devemos utilizar de todas as ferramentas sociais disponíveis para promover a reintegração social de forma a evitar quaisquer danos, seja ele de ordem biológica, social e/ ou principalmente psicológica. Nesse intuito, a família e o Estado devem unir esforços para ofertar uma oportunidade efetiva de mudança e acolhimento para esse grupo.

\section{IC II - Vivência no mundo das drogas}

A desconstrução do vínculo familiar associada às más influências do ciclo de amizade pode representar um passaporte para um caminho que, às vezes, não tem volta: o mundo das drogas. Contudo, as adolescentes sem um referencial levadas pelo vazio da carência afetiva e dores existenciais buscam na aprovação grupal a segurança, bem como a confiança recíproca e, principalmente, a elevação da autoestima.

Uma vez inseridas nesse contexto, ocorre 0 comprometimento e, até mesmo, a ruptura das relações interpessoais, dando margem à frustração e à decepção familiar. Diante do exposto, pode-se verificar o tamanho da experiência e comprometimento vivenciado por essas adolescentes:

DSC: Significação das drogas em relação às vivências:

Eu só vendia mesmo (...) quando a pessoa fica viciada, é uma coisa ruim que vem para destruir as familias, o mundo. Éo "satanás" b que fica atentando a pessoa para fumar. Eu mesma já fui usuária de drogas: maconha, crack, já cheirei pó, cheirei loló, botei "pico na veia" ', mas não tô usando mais nada. A pessoa começa com umas influências e depois fica dependente dela, querendo sair, mas não consegue. No meu pensamento, eu sabia que uma hora eu ia ser presa. Ficar devendo droga só gera violência! Eu vi isso na favela onde eu moro (...) 0 povo devendo e os cara matando. Teve uma menina lá perto de casa que empenhou a filha dela para fumar droga, isso é um absurdo... não é normal. 0 crack tá acabando com o mundo!

A inserção dessas jovens nas drogas se dá, muitas vezes, como um meio de comércio, uma forma de obter renda. Entretanto, quando sua relação está diretamente relacionada com o vício, a sua obsessão pela droga se constitui no que for necessário para sua obtenção, até mesmo, desfazer-se dos bens familiares. Dessa forma, a vivência nesse mundo obscuro culmina para marcas, às vezes, irreversíveis no que diz respeito a sua saúde física e, principalmente, mental, contribuindo, assim, para um desajuste no seu futuro pessoal.

Assim, estudar este fenômeno multidimensional que envolve as drogas na fase da adolescência, sob a perspectiva da saúde, significa compreender que as abordagens interdisciplinar 
$e$ intersetorial configuram-se como possibilidades de enfoque desta problemática. Neste cenário, o enfermeiro apresenta-se como "ator estratégico nas ações voltadas para este tema, no sentido de buscar abordagens que ampliem o olhar e as possibilidades de intervenção, sobretudo no nível de prevenção e promoção à saúde". ${ }^{16}$

\section{IC III - Processo de Institucionalização}

0 desenvolvimento de adolescentes carentes, instáveis e vulneráveis muitas vezes está associado a uma situação de desestruturação emocional, moral e afetiva provocada por fatores que interferem diretamente na formação do referencial do indivíduo como a família e o ambiente social através da ausência, do abandono e da violência. ${ }^{17}$ Para tanto, no convívio com as adolescentes em conflitos com a lei, deve-se levar em consideração seu contexto pessoal, familiar, social e cultural, enquanto perpassado por suas experiências de vida. ${ }^{18} \mathrm{Neste}$ contexto, têm-se, muitas vezes, os fatores condicionantes de sua situação de vida.

DSC: Motivos da sua vinda para a instituição:

Já vinham acontecendo alguns problemas por más influências do namoro, das amizades e também na minha casa. Eu vinha aprontando muito (...) caíno tráfico, nas drogas e formação de quadrilha. Saí de casa e para voltar minha mãe não queria mais. Tive que fazer alguma coisa para chamar a atenção! Chegou um momento que ninguém me aguentava mais e foram pedir ajuda.

0 discurso dessas adolescentes retrata uma singularidade vivenciada por esse grupo em conflito com a lei, quanto a desestruturação familiar marcada por um convívio conturbado, com a presença de poder negligente e contato afetivo raramente satisfatório.

Contudo, há poucas rotinas interacionais, levando ao comprometimento da comunicação em função de malentendidos, nas quais as opiniões não são aceitas e pouca atenção é dada às necessidades emocionais dos outros, culminando em um distanciamento das relações e descaracterizando a ideia de núcleo familiar.

Fica claro que, diante da ausência de um referencial familiar, as adolescentes passam a compor um grupo suscetível a influências do meio social no qual estão inseridas, como também na abrangência das relações interacionais que as mesmas passam a assumir em busca de um novo referencial, tais como namoros e grupos de pares. Por isso, nota-se no discurso uma justificativa do seu ato, projetandoo na supervalorização dos fatores subjetivos que levaram a realização da infração, amenizando sua ação, fugindo da sua responsabilidade.

Durante o internamento, a relação estabelecida com os funcionários e demais adolescentes revela-se, para algumas, como um ambiente de tolerância e respeito mútuo. Contudo, os relacionamentos sofrem modificações conforme as atitudes, sendo a convivência um fator que pode facilitar ou dificultar a interação interpessoal. Para algumas adolescentes, o convivio pode ser fonte de conflito; todavia, segundo os relatos, tratase de situações concernentes ao convivio de qualquer grupo social e suas relações intersubjetivas:

DSC: 0 convivio com os funcionários e com as outras adolescentes:

Considero as meninas da casa como minha família. São como umas irmãs para mim. Elas são amigas, me compreendem, sabem quando eu tô triste, quando eu tô alegre, me entendem como eu sou. Acho que todo mundo que você pensar aqui na casa é amigo, desde o Agente Socioeducativo (ASE) até a direção.(...) eu me dou bem com todo mundo, mas uma hora tá todo mundo de bem e outra hora tá todo mundo falando mal dos outros. Sem muitas arengas e discussões. Se fala direito e respeita, aí tem o respeito também. Algumas vezes, tanto os funcionários quanto as meninas estressam a gente. Os funcionários gostam de mandar muito só porque a gente tá cumprindo medida(...)

Pode-se notar, diante do discurso, que o abandono prévio das amizades existentes fora da casa leva a uma cautela na construção de novos relacionamentos, conduzindo algumas adolescentes a adotar um compor tamento mais resguardado. Entretanto, outras identificam, nesse cenário, uma oportunidade de estabelecer relações afetivas, substitutivas das carências vivenciadas no ambiente familiar.

Todavia, é interessante relatar que, como característica peculiar à fase da adolescência, depreende-se que a submissão a regras adquire um sentimento de não aceitação imediata, pois a disciplina rigorosa a todo o momento gera nos adolescentes, em sua maioria, uma inquietação e ao mesmo tempo uma tentativa de buscar sua individualidade.

\section{IC IV - Percepções Sobre o Comportamento Sexual}

Na adolescência, a sexualidade se manifesta em novas e surpreendentes sinestesias corporais, em desconhecidos desejos e nas novas necessidades de relacionamento interpessoal. A maneira como 0 adolescente vai lidar com a sua sexualidade, a maneira como vai expressá-la e vivê-la é influenciada por vários fatores, entre os quais estão a qualidade da relação emocional e afetiva que vivenciou com pessoas 
significativas na infância e no presente; as transformações psicológicas e cognitivas trazidas pelo crescimento e desenvolvimento; até os valores, normas morais e crenças da sociedade na qual ele está inserido. ${ }^{19}$

A vivência da sexualidade ainda é revestida de crenças, mitos, preconceitos e tabus; entretanto, as relações de gêneros desiguais e injustas são as que mais prejudicam o pleno desenvolvimento desta condição humana e originam características e vulnerabilidades particulares em adolescentes do sexo feminino. ${ }^{20}$

Evidencia-se o indivíduo, ser sexual, com todas as suas necessidades, potencialidades e especificidades da faixa evolutiva da adolescência, como centro do processo. A partir dele, com ele e para ele serão construídas as redes de educação preventiva, considerando-se o desenvolvimento de habilidades e práticas pessoais para viverem em sociedade e superarem problemas, e o reforço ou a mudança para atitudes positivas perante a saúde, vistas integralmente como indispensáveis à promoção de uma qualidade de vida saudável e prazerosa.

DSC: Problemas de saúde que podem ocorrer com mulheres ou adolescentes:

Na verdade, tem as Doenças Sexualmente Transmissíveis, eu convivo mais com isso por causa das histórias que eu conheço, mas tem bactéria, a AIDS, sifilis, corrimento, aquela gonorreia que pega com os homens no meio da rua. Só doenças ruins. Tem que se prevenir mesmo para não pegar doença e para não pegar "bucho"d. Usar camisinha para não pegar essas doenças... isso ébesteira da cabeça do povo dizer que atrapalha, que é ruim. Eu mesmo pego camisinha no (...) eu tomo injeção aqui pra me prevenir também da gravidez, que é mais importante ainda, porque DSTs tem cura e é só a gente se tratar, já engravidar cedo, a pessoa perde a infância toda, porque tem que parar de pensarna gente e pensar só no filho. Eu penso que é muita responsabilidade (...) e se a pessoa não tem trabalho não tem como sustentar a criança.

Em virtude da análise dos dados obtidos, depreendese que a relação conhecimento e realidade adquirem valor estimado pelas adolescentes, no que diz respeito à imediata ligação que elas fazem ao referirem doenças mais comumente presentes no cotidiano à sua experiência de vida quer seja ela participante da história ou produto do seu meio.

A questão da prevenção como forma de não adquirir doenças revela-se através dos discursos de maneira objetiva ao tipificar o consenso criado de que o conceito de prevenção de doenças, ainda hoje, assume conotação mais eloquente no ideário populacional, em detrimento da primeira ação a ser estabelecida e trabalhada: o contexto da promoção da saúde.
Tal medida visa ao fortalecimento do estado de saúde ao proporcionar a melhoria das condições de vida aliada à formação de um pensamento vinculado à conscientização da educação continuada e o desenvolvimento de uma postura mais responsável das atitudes assumidas nessa fase do ciclo evolutivo, a adolescência.

\section{IC V - Medidas de Assistência à Saúde}

Sabendo da importância de se manter um convívio harmônico e eficaz na instituição, promovendo assim um ambiente favorável para a reinserção social dessas adolescentes, não se deve esquecer a necessidade de se refletir sobre as ações que garantam a implementação das medidas de assistência à saúde, respeitando as particularidades do ser, como previsto no ECA.

A literatura sobre o tema proposto vem despontando nos trabalhos científicos nos últimos anos, e há também a portaria 1426/2004 $4^{21}$, a qual aprova as diretrizes para a implantação e implementação da atenção à saúde dos adolescentes em conflito com a lei, em regime de internação e internação provisória. De acordo com essa portaria, fica proposto que as ações e serviços de saúde tenham por finalidade promover a saúde dos adolescentes, oferecendo uma abordagem educativa, integral, humanizada e de qualidade.

Para o alcance dessa finalidade são estabelecidas as seguintes prioridades: a implantação de ações de promoção, proteção e recuperação da saúde do ser humano, em particular a saúde mental, a atenção aos agravos associados ao uso de álcool e outras drogas, redução de danos a saúde sexual e reprodutiva, atenção às DST/HIV/AIDS, distribuição de preservativos, vacinação, garantindo condições de salubridade e lazer, e a e garantia do acesso desses adolescentes em todos os níveis de atenção à saúde, por meio de referência e contrarreferência. $^{21}$

Diante dos questionamentos realizados às adolescentes quanto aos temas ou dúvidas que precisam ser trabalhados em relação à sua saúde, obtivemos os seguintes discursos:

DSC: Temas ou dúvidas em relação à saúde das adolescentes:

Eu acho que precisa falar sobre as doenças, todos os tipos de doenças. Queria saber mais sobre esse negócio da AIDS, como é que se pega e como se pegam as outras doenças.

Percebemos, através das falas que compuseram os discursos, a iniciativa por parte da instituição em atender aos requisitos da referida Portaria através da promoção e prevenção da saúde, ofertando palestras educativas, apoio psicopedagógico, áreas de lazer, além de manter contato com instituições de referência e contrarreferência relacionada à 
assistência a saúde, incentivo na inserção educacional e profissionalizante.

Pelos discursos das adolescentes, tem-se o reflexo das informações ofertadas durante o período de internação, as adolescentes reconhecem a importância da necessidade do conhecimento de saúde na sua vida como forma de prevenção e mesmo a busca pelo autocuidado. As informações absorvidas conduzem à edificação da conscientização dos seus direitos a uma vida saudável e, mais ainda, ao pleno exercício e efetivação deles.

Tal fundamentação e realidade existente podem ser reveladas mediante apresentação dos seguintes discursos: a saúde:

DSC: Cuidados e orientações necessárias para preservar

A gente tem palestras todo mês aqui falando sobre a saúde. Tem uma pessoa que é responsável por essas coisas, marca médico, leva a gente para ginecologista, para dentista, para fazer exame de sangue. Ela manda a gente passar num postinho quando for para casa, tomar vacina e se prevenir das Doenças Sexualmente Transmissíveis. Educadores também fazem orientações, mandam tomar banho todos os dias, lavar as mãos, se alimentar bem com alimentos saudáveis, almoçar, tomar café. Eles sempre falam do uso de drogas e da prevenção sexual. Eles mandam não fumar, tomar remédio de evitar, fazer exame de prevenção. Tem uma médica aqui, é uma doutora que vem ver a gente toda semana. Ela tira dúvida de qualquer coisa que a gente tá precisando, passa remédio, dá pomada às meninas, dá a injeção, dá a pílula também. Os remédios aqui é mais amostra grátis, mas dão!

Perante tais discursos, pode-se apreender do universo de significados expostos a importância da educação continuada nas ações de prevenção de doenças e promoção da saúde e, muito mais, levar tais adolescentes a adquirir um nível de conscientização e maturidade para distinguir essas duas ações de saúde no decorrer de sua vida. Essas distinções podem ser ressaltadas e valorizadas à medida que fornecem a otimização do trabalho prestado pela equipe de saúde.

A ação educativa em saúde está fundamentada no exercício da consciência política do profissional de saúde. É diante das diversidades e desafios presentes na realidade brasileira marcada pelas situações de pobreza e exclusão que o profissional comprometido com a educação em saúde deve ser capaz de apreender as vivências do real no universo subjetivo, entre desejos e aspirações dos seres humanos. Percebe-se vivências do real em um cenário que exige sua atitude diante dos fatos, deixando de ser mero expectador do espetáculo para se assumir como protagonista na transformação da realidade. A Educação em Saúde, assim, vem renovar os seres em evolução, caminhantes e perseverantes. ${ }^{22}$

\section{IC VI - Expectativas das Adolescentes quanto ao Futuro}

As expectativas das adolescentes, tendo-se por base as abordagens dos sentimentos e emoções em relação ao futuro, quanto ao término dos estudos, bem como ao ingresso em uma universidade, à constituição de um novo lar, à obtenção de um emprego, uma carreira, e, ainda, quanto ao futuro de forma global, são bastante otimistas, demonstrando confiança e motivação no alcance de seus objetivos com a finalidade de realizar seus sonhos.

DSC: Perspectivas sobre o futuro:

Eu penso em sair dessa vida de vez, me libertar, não quero mais decepcionar meus pais, minha família. Quero sair logo daqui, terminar os meus estudos, ter uma profissão, arrumar um emprego, ter meu dinheiro e conseguir minha independência. Também quero ter uma casa, um marido, ter filhos, ajudar minha familia, melhorar de vida, correr atrás dos meus objetivos para ter um futuro melhor!

Considerando a preponderante influência dos fatores socioeconômicos na ocorrência dos processos de exclusão social, a educação representa um instrumento de empoderamento do indivíduo e coletividade a partir de uma leitura crítica de sua realidade e da construção de propostas de transformação dessa realidade. ${ }^{15}$

Nessa perspectiva, é importante ressaltar que as adolescentes têm expectativas positivas quanto à necessidade de estabelecer um relacionamento afetivo estável e a constituição de seu próprio núcleo familiar. Para tanto, essas adolescentes veem na representação familiar um valor bastante estimado. Dessa forma, constata-se que estas almejam uma mudança no estilo de vida como um fator fundamental na consecuução da sua felicidade, o lado bom da vida até então desconhecido.

\section{CONCLUSÕES}

Através desse estudo, tornou-se relevante a formulação de aspectos que devem ser mais bem abordados no concernente à atuação integrada da equipe multiprofissional, na atenção à saúde prestada as adolescentes submetidas ao cumprimento de medidas socioeducativas. Daí a importância de inserir o enfermeiro como membro nesse processo. Para tanto, é essencial que, desde a sua preparação acadêmica até a sua rotina profissional, sejam desenvolvidas habilidades e 
competências que o conduzam ao discernimento no planejamento de ações de saúde comprometidas com a promoção da saúde destas adolescentes, alicerçadas no empoderamento e exercício de uma cidadania solidária.

\section{REFERÊNCIAS}

1.Ministério da Saúde (BR). Secretaria de Atenção à Saúde. Área de Saúde do Adolescente e do Jovem. Marco legal: saúde, um direito de adolescentes. Brasilia(DF); 2005.

2.Ministério da Saúde (BR). Secretaria de Atenção à Saúde. Departamento de Ações Programáticas Estratégicas. Marco teórico e referencial: saúde sexual e saúde reprodutiva de adolescentes e jovens. Brasília(DF); 2005.

3.Shoemaker DJ. Theories of delinquency: an examination of explanations of delinquent behavior. New York: Oxford University Press; 1996.

4.Lei $n^{\circ} 8.069$ de 13 de julho de 1990. Dispõe sobre o Estatuto da criança e do adolescente e dá outras providências. Diário Oficial da República Federativa do Brasil, Brasília (DF), 16 jul 1990: Seção 1.

5.olpani CF. A responsabilização penal do adolescente infrator e a ilusão de impunidade. Jus Navigandi [periódico on-line] 2003 dez; [citado 2009 out 30]; 8(162): [aprox.6 telas]. Disponível em: http:// jus2.uol.com.br/doutrina/texto.asp?id $=4600$

6.Machado MFAS, Monteiro EMLM, Queiroz DT, Vieira NFC, Barroso MGT. Integralidade, formação de saúde, educação em saúde e as propostas do SUS: uma revisão conceitual. Cienc Saude Colet. 2007; 12(2): 335-42.

7.Almeida Filho N. 0 conceito de saúde: ponto-cego da epidemiologia? Rev Bras Epidemiol. 2000 dez; 3(1-3): 4-20.

8. Minayo MCS. Pesquisa social: teoria, métodos e criatividade. $20^{\mathrm{a}} \mathrm{ed}$. Petrópolis(RJ): Vozes; 2002.

9. Fundação de Atendimento Sócioeducativo- FUNASE. Casas de Semiliberdade [citado 2008 ago 01]. Disponível em: http:// www.fundac.pe.gov.br/socio_atuacao.asp.

10. Ministério da Saúde(BR). Conselho Nacional de Saúde. Resolução n ${ }^{\circ}$ 196, de 10 de outubro de 1996. Diretrizes e normas regulamentadoras de pesquisas envolvendo seres humanos. Brasília(DF); 1996.

11. Lefèvre F, Lefèvre AMC. Depoimentos e discursos: uma proposta de análise em pesquisa social. Brasília (DF): Livro Aberto; 2005.

12. Lefèvre F, Lefèvre AMC. Discurso do sujeito coletivo: um novo enfoque em pesquisa qualitativa. $2^{\mathrm{a}}$ ed. Caxias do Sul: EDUCS; 2005.

13. Jordão AB. Vínculos familiares na adolescência: nuances e vicissitudes na clínica psicanalítica com adolescentes. Aletheia. [periódico on-line] 2008 jun; [citado 2009 out 29], (27):157-72. Disponível em: http:// pepsic.bvsalud.org/scielo
14. Gallo WAE, Albuquerque LC. Adolescentes em conflito com a lei: uma revisão dos fatores de risco para a conduta infracional. Psicologia: Teoria e Pratica 2005 jun;7(1): 81-95.

15. Monteiro EMLM, Brandão Neto W, Gomes IMB, Freitas RBN, Brady CL, Moraes MUB. Violência contra criança e adolescente: rompendo o silêncio. Rev RENE. 2009 jul/set; 10(3): 107-16.

16. Almeida Filho AJ, Ferreira MA, Gomes MLB, Silva RC, Santos TCF. 0 adolescente e as drogas: conseqüências para a saúde. Esc Anna Nery. 2007 dez; 11(4): 605-10.

17. Silva DFM, Hutz CS. Abuso infantil e comportamento delinqüente na adolescência: prevenção e intervenção. In: Hutz CS, organizador. Situações de risco e vulnerabilidade na infância e na adolescência: aspectos teóricos e estratégias de intervenção. São Paulo: Casa do Psicólogo; 2002. p.151185.

18. Priulli RMA, Moraes MS. Adolescentes em conflito com a lei. Cienc Saude Colet. 2007 set/out; 12(5):1185-195.

19. Serra ASL. Sexualidade e adolescência: adolescentes pensando juntos. Manual do facilitador. Brasília (DF): Secretaria de Saúde; 2003.

20. Torres CA, Beserra EP, Barroso, MGT. Percepções de adolescentes sobre a sua sexualidade. Esc Anna Nery. 2007 jun; 11 (2): 296 - 302.

21. Portaria Interministerial $n^{0} 1426$, de 14 de julho de 2004. Aprova as diretrizes para a implantação e implementação da atenção à saúde dos adolescentes em conflito com a lei, em regime de internação e internação provisória, e dá outras providências. Diário Oficial da República Federativa do Brasil, Brasília (DF), 15 jul 2004: Seção 1: 30.

22. Monteiro EMLM, Vieira NFC. Educação em saúde a partir de círculos de cultura. Rev Bras Enferm. 2010 jun; 63(3): 397-403.

\section{NOTAS}

aEstudo oriundo da Rede de Cooperação entre Programas de PósGraduação - UPE / USPRP / UFRJ com financiamento pelo PROCAD Novas Fronteiras CAPES 2009.

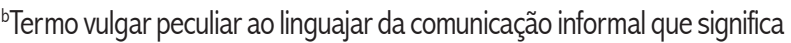
diabo, demônio, inimigo de Deus.

'Termo vulgar peculiar ao linguajar da comunicação informal que significa injetar substância ilícita na veia.

${ }^{\top}$ Termo vulgar peculiar ao linguajar da comunicação informal que significa gravidez. 